\title{
PENENTUAN PREMI DAN CADANGAN PADA ASURANSI PENDIDIKAN DENGAN MEMERHATIKAN PELUANG HIDUP ANAK
}

\author{
Ni Luh De Siska Sari Dewi ${ }^{1 \S}$, I Nyoman Widana ${ }^{2}$, Ketut Jayanegara ${ }^{3}$ \\ ${ }^{1}$ ProgramStudi Matematika, Fakultas MIPA - Universitas Udayana [Email: siskas ari1062@gmail.com] \\ ${ }^{2}$ ProgramStudi Matematika, Fakultas MIPA - Universitas Udayana [Email: nwidana@y ahoo.com] \\ ${ }^{3}$ ProgramStudi Matematika, Fakultas MIPA - Universitas Udayana [Email: ktjayanegara@unud.ac.id] \\ ${ }^{\S}$ Corresponding Author
}

\begin{abstract}
Education insurance provides services in the field of education. In education insurance, the insurednot only gets protection benefits but also education funds. These benefits will be received if they have paid premiums. Insurance companies also need to set the exact amount of policy value. The purpose of this study is to determine the premium and policy value of education insurance by taking into account the child's life chances. In this study, used secondary data from the 2011 Indonesian Mortality Table and illustrated data in the form of education fund data. Premium is obtained using the equivalenceprinciple and policy value is obtained using the prospective method. In the calculation of premiums and policy values for education insurance premiums by taking into account the child's life chances, modifications are made, the amount of education funds multiplied by the child's life chances. The results given in this study are the amount of education insurance premium by taking into account the child's life chances is $R p$ 6.946.456,00. Policy value increases during the disbursement of education funds and decreases at the end of coverage.
\end{abstract}

Keywords: Child's life chances, Education insurance, Policy value, Premium.

\section{PENDAHULUAN}

Perencanaan masa depan merupakan upaya untuk meminimalkan risiko. Menurut Kamus Besar Bahasa Indonesia (KBBI), definisi dari risiko adalah akibat yang kurang menyenangkan (merugikan, membahayakan) dari suatu perbuatan atau tindakan. Salah satu produk yang dapat menjadi solusi dalam upaya perencanaan masa depan adalah asuransi. Asuransi adalah pemindahan risiko dari tertanggung kepada perusahaan asuransi (Rejda \& McNamara, 2017). Pada asuransi, peserta asuransi atau yang disebut sebagai pihak tertanggung wajib membayar sejumlah uang yaitu premi kepada pihak penanggung (perusahaan asuransi).

Salah satu penunjang masa depan yang harus direncanakan dengan baik adalah pendidikan. Dalam menempuh pendidikan terdapat risiko yang mungkin terjadi. Mengingat pentingnya pendidikan dan risiko yang menyertainya maka perlu adanya suatu produk yang menjamin pendidikan seperti asuransi pendidikan yaitu asuransi jiwa yang memberikan pelayanan pada bidang pendidikan (Darmawi, 2006).

Perhitungan premi asuransi pendidikan
dalam artikel ini dilakukan dengan
memerhatikan peluang hidup anak. Hal ini
berarti dana pendidikan hanya cair apabila anak
masih hidup. Prinsip yang digunakan dalam
perhitungan premi asuransi pendidikan dengan
memerhatikan peluang hidup anak adalah
prinsip ekuivalensi (jumlah uang yang masuk ke
perusahaan sama dengan jumlah uang yang
keluar dari perusahaan). Selain premi, dalam
artikel ini juga ditentukan cadangan premi
asuransi pendidikan. Menurut Sembiring
(1986), cadangan premi adalah selisih nilai
santunan dan nilai tunai pembayaran pada waktu
pertanggungan. Metode yang digunakan untuk
menentukan cadangan premi asuransi
pendidikan dalam artikel ini adalah metode
prospektif, yaitu metode yang didasarkan pada
nilai sekarang dari total pendapatan di waktu
yang akan datang (Futami, 1993). Tujuan dari
penelitian ini yaitu menentukan premi dan
cadangan pada asuransi pendidikan dengan
memerhatikan peluang hidup anak.


Dalam artikel ini akan ditentukan nilai premi yang dibayarkan setiap tahun hingga akhir kontrak dengan syarat yang menjadi tertanggung masih hidup disebut sebagai premi tahunan bersih asuransi jiwa endowment. Perhitungan dilakukan dengan menggunakan simbol-simbol komutasi yaitu bentuk sederhana dari persamaan asuransi. Menurut Futami (1993), simbolsimbol komutasi yaitu sebagai berikut:

$$
\begin{aligned}
& D_{x}=v^{x} l_{x} \\
& N_{x}=D_{x}+D_{x+1}+D_{x+2}+\cdots \\
& C_{x}=v^{x+1} d_{x} \\
& M_{x}=C_{x}+C_{x+1}+C_{x+2}+\cdots
\end{aligned}
$$

Besar premi tahunan bersih asuransi jiwa endowment adalah:

$$
P_{x: \bar{n} \mid}=\frac{A_{x: \bar{n} \mid}}{\ddot{a}_{x: \bar{n} \mid}}
$$

dengan anuitas berjangka awal tahun:

$$
\ddot{a}_{x: \bar{n} \mid}=\frac{N_{x}-N_{x+n}}{D_{x}}
$$

dan besarnya manfaat asuransi jiw a endow ment adalah sebagai berikut:

$$
A_{x: \overline{n \mid}}=\frac{M_{x}-M_{x+n}+D_{x+n}}{D_{x}}
$$

Menurut Futami (1994), premi tahunan pada asuransi joint life dwiguna adalah:

$$
P_{x y: \bar{n} \mid}=\frac{A_{x y: \bar{n} \mid}}{\ddot{a}_{x y: \bar{n} \mid}}
$$

dengan anuitas berjangka awal tahun:

$$
\ddot{a}_{x y: \bar{n} \mid}=\frac{N_{x y}-N_{x+n, y+n}}{D_{x y}}
$$

dan besarnya manfaat asuransi jiw a endow ment adalah:

$$
A_{x y: \bar{n} \mid}=\frac{M_{x y}-M_{x+n, y+n}+D_{x+n, y+n}}{D_{x y}}
$$

Simbol-simbol komutasi untuk asuransi joint life adalah sebagai berikut:

$$
\begin{aligned}
D_{x y}= & v^{\frac{1}{2}(x+y)} l_{x y} \\
N_{x y}= & D_{x y}+D_{x+1, y+1}+\cdots \\
C_{x y}= & v^{\frac{1}{2}(x+y)+1} d_{x y} \\
& \quad M_{x y}=C_{x y}+C_{x+1, y+1}+\cdots
\end{aligned}
$$

Setelah dilakukan perhitungan premi, dapat ditentukan nilai dari cadangan premi. Cadangan premi yang didasarkan pada nilai sekarang dari total pengeluaran perusahaan di waktu yang akan datang dikurangi nilai sekarang dari total pendapatan perusahaan di waktu yang akan datang disebut metode prospektif. Besar cadangan premi pada tahun ke- $t$ berdasarkan metode prospektif adalah:

$$
{ }_{t} V_{x: \overline{n \mid}}=A_{x+t, \overline{n-t \mid}}-P_{x: \bar{n} \mid} \ddot{a}_{x+t, \overline{n-t \mid}}
$$

Cadangan premi untuk asuransi joint life dengan metode prospektif:

$$
\begin{aligned}
{ }_{t} V= & A_{x+t, y+t: \overline{n-t \mid}} \\
& -P_{x y: \bar{n} \mid} \ddot{a}_{x+t, y+t: \overline{n-t \mid}}
\end{aligned}
$$

\section{METODE PENELITIAN}

Dalam penelitian ini, data yang digunakan adalah data sekunder. Data tersebut berupa data peluang kematian yang bersumber dari Tabel Mortalitas Indonesia 2011. Selain itu, penelitian ini juga menggunakan data ilustrasi berupa dana pendidikan yang akan diperoleh tertanggung bersumber dari polis perusahaan asuransi. Langkah-langkah yang digunakan dalam penelitian ini adalah:

1. Menggunakan polis perusahaan asuransi terkait dana pendidikan pasti.

2. Menggunakan Tabel Mortalitas Indonesia 2011 untuk memperoleh tabel komutasi asuransi pendidikan.

3. Menghitung premi tahunan pada asuransi pendidikan tanpa memerhatikan peluang hidup anak (berdasarkan persamaan (1)).

4. Menentukan formula premi pada asuransi pendidikan dengan memerhatikan peluang hidup anak menggunakan prinsip ekuivalensi.

5. Menghitung nilai premi pada asuransi pendidikan dengan memerhatikan peluang hidup anak berdasarkan formula yang diperoleh.

6. Menghitung cadangan premi asuransi pendidikan dengan metode prospektif tanpa memerhatikan peluang hidup anak (berdasarkan persamaan (3)).

7. Menentukan formula cadangan premi asuransi pendidikan dengan memerhatikan peluang hidup anak menggunakan metode prospektif.

8. Menghitung cadangan premi asuransi pendidikan dengan memerhatikan peluang hidup anak berdasarkan formula yang diperoleh. 


\section{HASIL DAN PEMBAHASAN}

\subsection{Perhitungan Premi Tahunan Tanpa Memerhatikan Peluang Hidup Anak}

Polis yang digunakan pada perhitungan premi tahunan asuransi pendidikan tanpa memerhatikan peluang hidup anak dalam kasus ini adalah: pihak tertanggung dengan usia 39 tahun mengikuti asuransi pendidikan dalam jangka waktu 22 tahun. Dana pendidikan yang didapat tertanggung adalah 5\% dari uang pertanggungan pada akhir tahun ke empat, $10 \%$ dari uang pertanggungan pada akhir tahun ke enam, 20\% dari uang pertanggungan pada akhir tahun ke-12, 30\% pada akhir tahun ke-15, 50\% pada akhir tahun ke-18, 25\% pada akhir tahunke 19,20 , dan 21 , serta $40 \%$ pada akhir tahunke 22 . Tertanggung yang meninggal dalam masa pertanggungan, akan menerima santunan sebesar $100 \%$ dari uang pertanggungan yaitu sebesar $\mathrm{Rp}$ $30.000 .000,00$. Masa pembayaran premi enam tahun, tingkat suku bunga $3,5 \%$.

Berdasarkan polis yang ditetapkan, maka persamaan (1) dapat dimodifikasi menjadi:

$$
\begin{aligned}
P_{39: \overline{6 \mid}}= & \frac{3 \times 10^{7}\left(A_{39: \overline{22 \mid}}^{1}\right)+A P^{(0)}}{\ddot{a}_{39: \overline{6} \mid}} \\
= & \frac{3 \times 10^{7}\left(\frac{M_{39}-M_{61}}{D_{39}}\right)+A P^{(0)}}{\frac{N_{39}-N_{45}}{D_{39}}}
\end{aligned}
$$

dengan $A P^{(0)}$ adalah nilai tunai dari besar manfaat pendidikan tanpa memerhatikan hidup atau matinya anak dan besarnya adalah:

$$
\begin{aligned}
A P^{(0)}=3 \times 10^{7} & \left(0,05 v^{4}+0,1 v^{6}+0,2 v^{12}\right. \\
& +0,3 v^{15}+0,5 v^{18}+0,25 v^{19} \\
& +0,25 v^{20}+0,25 v^{21} \\
& \left.+0,4 v^{22}\right)
\end{aligned}
$$

Sehingga diperoleh besar premi asuransi pendidikan tanpa memerhatikan peluang hidup anak adalah:

$$
\begin{aligned}
P_{39: \overline{6} \mid} & =\frac{2298057,8890+38107798,8800}{5,4938} \\
& =7354815,1850
\end{aligned}
$$

\subsection{Penentuan Premi Asuransi Pendidikan dengan Memerhatikan Peluang Hidup Anak}

Polis yang digunakan pada perhitungan premi tahunan asuransi pendidikan dengan memerhatikan peluang hidup anak sama seperti polis pada perhitungan premi tanpa memerhatikan peluang hidup anak, hanya saja dalam hal ini seorang ayah berusia 39 tahun mengikuti asuransi pendidikan pada saat anak berusia 0 tahun. Santunan diterima sebesar $100 \%$ dari uang pertanggungan apabila anak yang menjadi tertanggung meninggal dalam masa pertanggungan, dan dana pendidikan diterima apabila anak yang menjadi tertanggung masih hidup.

Dalam penentuan premi asuransi pendidikan dengan memerhatikan peluang hidup anak ditentukan terlebih dahulu peluang hidup anak mencapai usia tertentu. Menggunakan persamaan:

$$
{ }_{n} p_{x}=\frac{l_{x+n}}{l_{x}}
$$

dengan $l_{x}$ adalah jumlah orang berusia $x$ tahun dan $l_{x+n}$ adalah jumlah orang berusia $x+n$ tahun.

Premi ditentukan berdasarkan prinspip ekuivalensi. Menurut Dickson et al. (2009), prinsip ekuivalensi dinyatakan sebagai:

$$
E(Y)=E(Z)
$$

dengan $Z$ adalah nilai tunai manfaat, dan $Y$ adalah nilai tunai premi. Oleh karena itu, berdasarkan polis yang telah ditetapkan premi asuransi pendidikan dinyatakan sebagai:

$$
P=\frac{S \cdot A_{x: \overline{n \mid}}^{1}+A P^{(1)}}{\ddot{a}_{x y: \bar{m} \mid}}
$$

dengan $S$ adalah besarnya santunan yang akan diperoleh tertanggung, $m$ adalah jangka waktu pembayaran premi, $A P^{(1)}$ adalah nilai tunai dari besar manfaat pendidikan dengan memerhatikan hidup atau matinya anak yang menjadi tertanggung dan besarnya adalah:

$$
\begin{aligned}
A P^{(1)}=3 \times 10^{7} & \left(0,05 v^{4}{ }_{4} p_{0}+0,1 v^{6}{ }_{6} p_{0}\right. \\
& +0,2 v^{12}{ }_{12} p_{0}+0,3 v^{15}{ }_{15} p_{0} \\
& +0,5 v v^{18}{ }_{18} p_{0}+0,25 v^{19}{ }_{19} p_{0} \\
& +0,25 v^{20}{ }_{20} p_{0}+0,25 v^{21}{ }_{21} p_{0} \\
& +0,4 v^{22}{ }_{22} p_{0}
\end{aligned}
$$

Sehingga diperoleh besar premi dengan memerhatikan peluang hidup anak sesuai polis yaitu:

$$
\begin{aligned}
P & =\frac{3 \times 10^{7}\left(A_{0: \overline{22 \mid}}^{1}\right)+A P^{(1)}}{\ddot{a}_{0,39: \overline{6} \mid}} \\
& =6946456,266
\end{aligned}
$$




\subsection{Perhitungan Cadangan Premi Tanpa Memerhatikan Peluang Hidup Anak}

Berdasarkan polis yang ditetapkan, maka persamaan (3) dapat dimodifikasi menjadi:

$$
\begin{gathered}
{ }_{t} V_{39: \overline{22 \mid}}=S . A_{39+t}^{1} \overline{22-t \mid}-P \ddot{a}_{39+t: \overline{6-t \mid}} \\
+A P_{t}^{(0)}
\end{gathered}
$$

dengan $A P_{t}^{(0)}$ merupakan nilai tunai dari besar manfaat pendidikan tanpa memerhatikan hidup atau matinya anak pada tahun ke- $t$.

untuk $\mathrm{t}=1,2,3,4$

$$
\begin{aligned}
A P_{t}^{(0)}=3 \times 10^{7} & \left(0,05 v^{4-t}+0,1 v^{6-t}\right. \\
& +0,2 v^{12-t}+0,3 v^{15-t} \\
& +0,5 v^{18-t}+0,25 v^{19-t} \\
& +0,25 v^{20-t}+0,25 v^{21-t} \\
& \left.+0,4 v^{22-t}\right)
\end{aligned}
$$

untuk $\mathrm{t}=5,6$

$$
\begin{aligned}
A P_{t}^{(0)}=3 \times 10^{7} & \left(0,1 v^{6-t}+0,2 v^{12-t}\right. \\
& +0,3 v^{15-t}+0,5 v^{18-t} \\
& +0,25 v^{19-t}+0,25 v^{20-t} \\
& \left.+0,25 v^{21-t}+0,4 v^{22-t}\right)
\end{aligned}
$$

untuk $\mathrm{t}=7,8,9,10,11,12$

$$
\begin{aligned}
A P_{t}^{(0)}=3 \times 10^{7} & \left(0,2 v^{12-t}+0,3 v^{15-t}\right. \\
& +0,5 v^{18-t}+0,25 v^{19-t} \\
& +0,25 v^{20-t}+0,25 v^{21-t} \\
& \left.+0,4 v^{22-t}\right)
\end{aligned}
$$

untuk $\mathrm{t}=13,14,15$

$$
\begin{aligned}
A P_{t}^{(0)}=3 \times 10^{7} & \left(0,3 v^{15-t}+0,5 v^{18-t}\right. \\
& +0,25 v^{19-t}+0,25 v^{20-t} \\
& \left.+0,25 v^{21-t}+0,4 v^{22-t}\right)
\end{aligned}
$$

untuk $\mathrm{t}=16,17,18$

$$
\begin{aligned}
A P_{t}^{(0)}=3 \times 10^{7} & \left(0,5 v^{18-t}+0,25 v^{19-t}\right. \\
& +0,25 v^{20-t}+0,25 v^{21-t} \\
& \left.+0,4 v^{22-t}\right)
\end{aligned}
$$

untuk $\mathrm{t}=19$

$$
\begin{array}{r}
A P_{t}^{(0)}=3 \times 10^{7}\left(0,25 v^{19-t}+0,25 v^{20-t}\right. \\
\left.+0,25 v^{21-t}+0,4 v^{22-t}\right)
\end{array}
$$

untuk $\mathrm{t}=20$

$$
\begin{gathered}
A P_{t}^{(0)}=3 \times 10^{7}\left(0,25 v^{20-t}+0,25 v^{21-t}\right. \\
\left.+0,4 v^{22-t}\right)
\end{gathered}
$$

untuk $\mathrm{t}=21$

$$
A P_{t}^{(0)}=3 \times 10^{7}\left(0,25 v^{21-t}+0,4 v^{22-t}\right)
$$

untuk $\mathrm{t}=22$

$$
A P_{t}^{(0)}=3 \times 10^{7}\left(0,4 v^{22-t}\right)
$$

Sehingga diperoleh besar cadangan premi seperti pada Gambar 1.

\section{CADANGAN ASURANSI PENDIDIKAN TANPA} MEMERHATIKAN PELUANG HIDUP ANAK

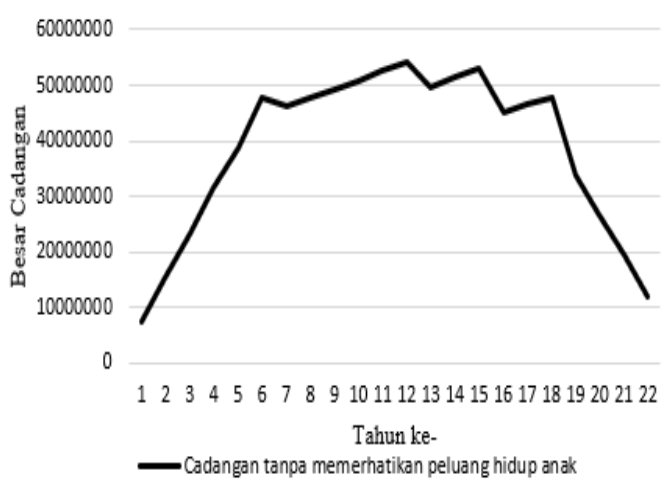

Gambar 1. Cadangan TanpaMemerhatikan Peluang Hidup Anak

\subsection{Perhitungan Cadangan Premi dengan Memerhatikan Peluang Hidup Anak}

Berdasarkan polis yang ditetapkan, maka persamaan (4) dapat dimodifikasi menjadi:

$$
\begin{gathered}
{ }_{t} V_{0,39: \overline{22 \mid}}=S . A_{0+t: \overline{22-t \mid}}^{1}-P \ddot{a}_{0+t, 39+t: \overline{6-t \mid}} \\
+A P_{t}^{(1)}
\end{gathered}
$$

untuk $\mathrm{t}=1,2,3,4$

$$
\begin{aligned}
A P_{t}^{(1)}=3 \times 10^{7} & \left(0,05 v^{4-t}{ }_{4-t} p_{0}\right. \\
& +0,1 v^{6-t}{ }_{6-t} p_{0} \\
& +0,2 v^{12-t}{ }_{12-t} p_{0}+\cdots \\
& \left.+0,4 v^{22-t}{ }_{22-t} p_{0}\right)
\end{aligned}
$$

untuk $\mathrm{t}=5,6$

$$
\begin{aligned}
A P_{t}^{(1)}=3 \times 10^{7} & \left(0,1 v^{6-t}{ }_{6-t} p_{0}\right. \\
& +0,2 v^{12-t}{ }_{12-t} p_{0}+\cdots \\
& \left.+0,4 v^{22-t}{ }_{22-t} p_{0}\right)
\end{aligned}
$$

untuk $\mathrm{t}=7,8,9,10,11,12$

$$
\begin{aligned}
A P_{t}^{(1)}=3 \times 10^{7} & \left(0,2 v^{12-t}{ }_{12-t} p_{0}\right. \\
& +0,3 v^{15-t}{ }_{15-t} p_{0} \\
& +0,5 v^{18-t}{ }_{18-t} p_{0}+\cdots \\
& \left.+0,4 v^{22-t}{ }_{22-t} p_{0}\right)
\end{aligned}
$$

untuk $\mathrm{t}=13,14,15$

$$
\begin{aligned}
A P_{t}^{(1)}=3 \times 10^{7} & \left(0,3 v^{15-t}{ }_{15-t} p_{0}\right. \\
& +0,5 v^{18-t}{ }_{18-t} p_{0} \\
& +0,25 v^{19-t}{ }_{19-t} p_{0}+\cdots \\
& \left.+0,4 v^{22-t}{ }_{22-t} p_{0}\right)
\end{aligned}
$$


untuk $\mathrm{t}=16,17,18$

$$
\begin{aligned}
A P_{t}^{(1)}=3 \times 10^{7} & \left(0,5 v^{18-t}{ }_{18-t} p_{0}\right. \\
& +0,25 v^{19-t}{ }_{19-t} p_{0} \\
& +0,25 v^{20-t}{ }_{20-t} p_{0} \\
& +0,25 v^{21-t}{ }_{21-t} p_{0} \\
& \left.+0,4 v^{22-t}{ }_{22-t} p_{0}\right)
\end{aligned}
$$

untuk $\mathrm{t}=19$

$$
\begin{aligned}
A P_{t}^{(1)}=3 \times 10^{7} & \left(0,25 v^{19-t}{ }_{19-t} p_{0}\right. \\
& +0,25 v^{20-t}{ }_{20-t} p_{0} \\
& +0,25 v^{21-t}{ }_{21-t} p_{0} \\
& \left.+0,4 v^{22-t}{ }_{22-t} p_{0}\right)
\end{aligned}
$$

untuk $\mathrm{t}=20$

$$
\begin{aligned}
A P_{t}^{(1)}=3 \times 10^{7} & \left(0,25 v^{20-t}{ }_{20-t} p_{0}\right. \\
& +0,25 v^{21-t}{ }_{21-t} p_{0} \\
& \left.+0,4 v^{22-t}{ }_{22-t} p_{0}\right)
\end{aligned}
$$

untuk $\mathrm{t}=21$

$$
\begin{array}{r}
A P_{t}^{(1)}=3 \times 10^{7}\left(0,25 v^{21-t}{ }_{21-t} p_{0}\right. \\
\left.+0,4 v^{22-t}{ }_{22-t} p_{0}\right)
\end{array}
$$

untuk $\mathrm{t}=22$

$$
A P_{t}^{(1)}=3 \times 10^{7}\left(0,4 v^{22-t}{ }_{22-t} p_{0}\right)
$$

Sehingga diperoleh cadangan dengan memerhatikan peluang hidup anak pada tahun pertama yaitu sebagai berikut:

$$
\begin{aligned}
{ }_{1} V_{0,39: \overline{22 \mid}} & =S \cdot A_{1: \overline{21 \mid}}^{1}-P \ddot{a}_{1,40: 5}+A P_{1}^{(1)} \\
& =6926183,0530
\end{aligned}
$$

Diperoleh cadangan premi pada tahun pertama dengan memerhatikan peluang hidup anak yaitu $R p$ 6.926.183,00. Besar cadangan premi dengan memerhatikan peluang hidup anak dapat diperhatikan pada Gambar 2.

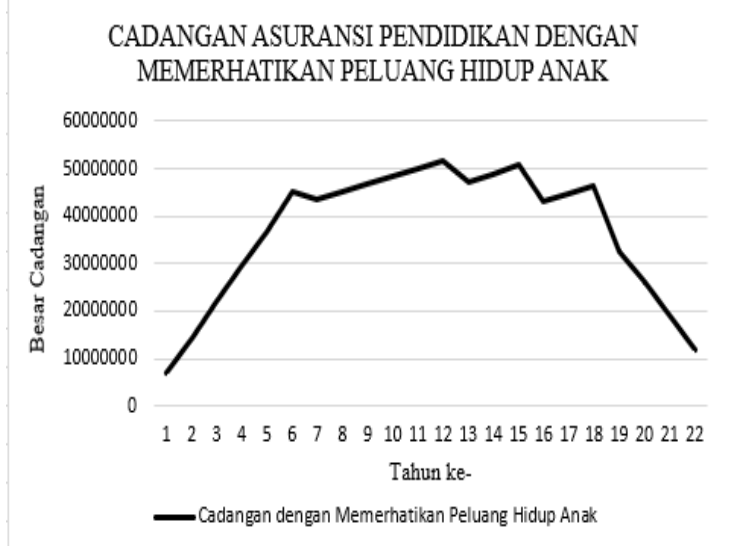

Gambar 2. Cadangan dengan Memerhatikan Peluang Hidup Anak

\section{KESIMPULAN DAN SARAN}

Kesimpulan yang diperoleh pada artikel ini adalah premi pada asuransi pendidikan dengan memerhatikan peluang hidup anak dapat ditentukan berdasarkan persamaan:

$$
P \quad=\frac{S \cdot A_{x: \overline{n \mid}}^{1}+A P^{(1)}}{\ddot{a}_{x y: \bar{m} \mid}}
$$

Besar premi asuransi pendidikan berdasarkan formula yang diperoleh yaitu $R p$ 6.946.456,00. Cadangan premi asuransi pendidikan dengan memerhatikan peluang hidup anak dapat ditentukan dengan menggunakan persamaan:

$$
\begin{gathered}
{ }_{t} V_{x, y: \bar{n} \mid}=S \cdot A_{x+t: \overline{n-t \mid}}^{1}-P \ddot{a}_{x+t, y+t: \overline{m-t \mid}} \\
+A P_{t}^{(1)}
\end{gathered}
$$

Besar cadangan premi pada tahun pertama dengan memerhatikan peluang hidup anak yaitu $R p$ 6.926.183,00. Nilai cadangan premi menjadi lebih tinggi pada tahun-tahun pencairan dana pendidikan.

Pada penelitian ini tingkat suku bunga yang digunakan dalam perhitungan diasumsikan konstan. Pada kenyataannya tingkat suku bunga seringkali mengalami perubahan karena berbagai faktor. Disarankan dalam penelitian selanjutnya perhitungan dikembangkan dengan menggunakan tingkat suku bunga tidak konstan.

\section{DAFTAR PUSTAKA}

Darmawi, H. 2006. Manajemen Asuransi. Jakarta: Bumi Aksara.

Dickson, D. C. ., Hardy, M. R., \& Waters, H. R. 2009. Actuarial Mathematics for Life Contingent Risks. New York: Cambridge University Press.

Futami, T. 1993. Matematika Asuransi Jiwa, Bagian I. 1st ed. Tokyo: Oriental Life Insurance Cultural Development Center.

Futami, T. 1994. Matematika Asuransi Jiwa, Bagian II. 2nd ed. Tokyo: Oriental Life Insurance Cultural Development Center.

Kamus Besar Bahasa Indonesia. [Online]. Tersedia di https://kbbi.web.id. Diakses 9 September 2020.

Rejda, G. E., \& McNamara, M. . 2017. Principles of Risk Management and Insurance. Harlow: Pearson.

Sembiring, R. K. 1986. Buku Materi Pokok Asuransi I. Jakarta: Universitas Terbuka. 